\title{
XXXVIII. Note on the theory of the solitary wave
}

\section{Sir G. G. Stokes}

To cite this article: Sir G. G. Stokes (1891) XXXVIII. Note on the theory of the solitary wave , Philosophical Magazine Series 5, 32:196, 314-316, DOI: 10.1080/14786449108620186

To link to this article: http://dx.doi.org/10.1080/14786449108620186

曲 Published online: 08 May 2009.

Submit your article to this journal

Џ Article views: 8

Q View related articles $₫$ 
XXXVIII. Note on the Theory of the Solitary Wave.

$B y$ Sir G. G. Stokes*.

T a paper on the Solitary Wave by Mr. J. McCowan, printed in the July number of the Philosophical Magazine, for a copy of which I am indebted to the kindness of the author, he refers to a conclusion which I advanced in a paper written long since, and reprinted full ten years ago, according to which a solitary wave could not be propagated without change of form. As I have known for the last ten years that this conclusion was erroneous, and have published a paper in which the motion of a uniformly propagated solitary wave was considered, I am not concerned to defend it; but it may be well to point out the true source of the error, respecting which I cannot agree with Mr. MeCowan.

While the first volume of my Collected Papers was going through the press, I was led to the conclusion (see p. 227) that the highest possible waves of the oscillatory kind (the motion being irrotational) presented $a$ form in which the crests came to wedges of $120^{\circ}$. On reflecting on the application of this to very long waves propagated in water of which the depth is small compared with the length of wave, I was led to perceive that the conclusion above mentioned was erroneous, and also that the source of the error was that it was not sufficient, even though a solitary wave were very long, to treat it as indefinitely long, and consequently to take the horizontal velocity as the same from the surface to the bottom. On speaking on the subject to Lord Rayleigh, he referred me to the previous papers on the solitary wave by M. Bonssinesq and himself, with which I was not at the time acquainted. The conclusion of a supplement to my paper on oscillatory waves, which forms the last article in vol. i., shows that I was then fully alive to the possibility of the propagation of a solitary wave without change; and in a short paper entitled "On the highest wave of uniform propagation (Preliminary notice)," read before the Cambridge Philosophical Society in 1883, and printed in the Proceedings (vol. iv. p. 361), I have indicated a new method, depending on a process of trial and error, for determining numerically the circumstances of uniform propagation of waves, whether of the oscillatory or solitary class, more especially in the extreme case in which the crest comes to a wedge of $120^{\circ}$, so that the wave is on the point of beginning to break.

I cannot agree with Mr. McCowan either that the form of expansion which I used is inadmissible, or that the form which he proposes at p. 58 to substitute, that of a series involving exponentials in which the coefficient of $x$ in the index is

* Communicated by the Author. 
Sir G. G. Stokes on the Theory of the Solitary Wave. 315

real, is (at least for my purpose) admissible. It is not true that a non-periodic function of $x$ cannot be expressed by means of periodic functions; for example, the non-periodic function $e^{-x^{a}}$ may be expanded in the definite integral

$$
e^{-\alpha^{2}}=\frac{2}{\sqrt{ } \pi} \int_{0}^{\infty} e^{-\alpha^{2}} \cos 2 \alpha x \cdot d \alpha,
$$

each element of which is periodic. On the other hand, the form of expansion proposed by Mr. McCowan is (at least for my purpose) inadmissible, on account of the discontinuity of the expression.

I will now mention more particularly the step which led me to a wrong conclusion. It is easily shown that in a very long wave propagated in water the depth of which is small compared with the length of the wave, the horizontal velucity is nearly the same from the bottom to the surface for any vertical section of the wave made by a plane perpendicular to the direction of propagation. For a given depth of water and maximum height of wave, this is so much the more nearly true as the length of the wave is greater. The horizontal velocity tends indefinitely towards constancy from top to bottoni as the length of the wave increases indetinitely. Now Sir George Airy has shown that for a wave in which we may suppose the particles in a vertical plane to remain always in a vertical plane, as they must do if the horizontal velocity is the same from top to bottom, the form of the wave must gradually change as it progresses. It might seem therefore that, however small we take the height of a wave at the highest point, we have only to make the wave long enough and Airy's investigation will apply, and the wave will change its form in time as it travels along. Now in the solitary wave of Russell, the lower the wave, the longer it is ; and therefore it might ssem as if we had only to make the wave low enough and long enough and the length would be so great that Airy's investigation would apply, and the form would change, though slowly.

'The answer to this is that, however small we take the height, we are not at liberty to increase the length indefinituly. There is in fact a relation between the height and the length in a solitary wave which can be propagaterl uniformly, which, though it is of such a nature that the length becomes infinite when the height becomes infinitely small, nevertheless forbids us for a given height, however small, to increase the length indefinitely.

The possibility of the existence of a solitary wave of uniform propagation is so far established by my investigation relating to oscillatory waves, as that it is made to depend on the principle that the infinite series by which the cireumstances of the 
motion of oscillatory waves is expressed must remain convergent until the height is so far increased that the outline presents a singular point, namely the wedge of $120^{\circ}$. If this be conceded, we have only to make the wave-length (in the sense of the distance from crest to erest, not in that of the distance from the point where one of the swells begins to where it ceases to by sensible) infinite, in order to pass to the case of a solitary wave uniformly propagated.

XXXIX. Notices respecting New Books.

(i.) A T'reatise on Trigonometry. (Fifth edition, pp. viii+160.)

(ii.) A Treatise on Algebra. (Second edition, pp. viii +412.)

(iii.) Logarithmic Tables. (Third edition, pp. 96.)

THESE are three works, (i.) and (ii.) written by Profs. Oliver, Wait, and Jones, of Cornell University, and (iii.) arranged by the last-named gentJeman, who has recently been on a visit to this country with a view, we believe, to the preparation of a new edition of the Tables. (i.) is an excellent practical treatise on both Plane and Spherical Trigonometry. "After eight years' use in the class-rooms the book has been wholly sewritten." The aim in the revision has been to make the book "simpler and more attractive as a text-book, and to make it more thorough and exhaustive as a treatise." The new matter is thus noticed:-(1) Applications of Trigonometry to surveying, astronomy, and navigation. (2) The extension of the uotion of directed lines, and the introduction of such other conventions, particularly of directed surfaces, as help to interpret algebraic symbols by geometric magnitudes, and thus to lay the foundation for the study of mathematical physics. (3) The discussion of the general triangle, plane and spherical. There is no lack of admirably drawn figures, and often the same principle is illustrated by several figures: when this is the case, " the first figure is easiest followed; the uthers help the reader to see the generality of the principle and of the proof." The text is concise without being obscure. "Only the main lines of the subject are developed; collateral matters are outlined in the examples and left for the student to work out for himself." The authors have freely used English text-books as well as American ones, and largely drawn upon Senate-House Examination-papers. It is a work especially adapted for practical students. There is a copious Index of reference.

(ii.) This edition appears to be almost, if not quite, identical with the first edition, which we commended some few years since in our Magazine.

(iii.) is a very bandy collection of most useful Tables. There is an explanation of the 'lables at the end of the work, and on the title-page there is the promise of a dollar for the first notice of every error in the Tables.

The same three writers promise a text-book in Algebra whose dofinitions and statements of principles are clear and precise, and wbose proofs are rigorous and so simple that any diligent pupil can read it 